\title{
Depth of colorectal-wall invasion and lymph-node involvement as major outcome factors influencing surgical strategy in patients with advanced and recurrent ovarian cancer with diffuse peritoneal metastases
}

Angelo Di Giorgio ${ }^{1}$, Maurizio Cardi ${ }^{1}$, Daniele Biacchi ${ }^{1}$, Simone Sibio ${ }^{1}$, Fabio Accarpio ${ }^{1}$, Antonio Ciardi², Tommaso Cornali ${ }^{1}$, Marialuisa Framarino ${ }^{3}$ and Paolo Sammartino ${ }^{*}$

\begin{abstract}
Background: More information is needed on the anatomopathological outcome variables indicating the appropriate surgical strategy for the colorectal resections often needed during cytoreduction for ovarian cancer.

Methods: From a phase-II study cohort including 70 patients with primary advanced or recurrent ovarian cancer with diffuse peritoneal metastases treated from November 2000 to April 2009, we selected for this study the 52 consecutive patients who needed colorectal resection. Data collected included type of colorectal resection, peritoneal cancer index (PCI), histopathology (depth of bowel-wall invasion and lymph-node spread), cytoreduction rate and outcome. Correlations were tested between possible prognostic factors and Kaplan-Meier five-year overall and disease-free survival. A Cox multivariate regression model was used to identify independent variables associated with outcome.

Results: In the 52 patients, the optimal cytoreduction rate was $86.5 \%$ (CCO/1). In all patients, implants infiltrated deeply into the bowel wall, in $75 \%$ of the cases up to the muscular and mucosal layer. Lymph-node metastases were detected in $50 \%$ of the cases; mesenteric nodes were involved in $42.3 \%$. Most patients (52\%) had an uneventful postoperative course. Operative mortality was 3.8\%. The five-year survival rate was $49.9 \%$ and five-year disease-free survival was $36.7 \%$. Cox regression analysis identified as the main prognostic factors completeness of cytoreduction and depth of bowel wall invasion.
\end{abstract}

Conclusions: Our findings suggest that the major independent prognostic factors in patients with advanced ovarian cancer needing colorectal resections are completeness of cytoreduction and depth of bowel wall invasion. Surgical management and pathological assessment should be aware of and deal with dual locoregional and mesenteric lymphatic spread.

Keywords: Ovarian cancer, Peritoneal metastases, Colorectal resection, Depth of bowel wall invasion, Mesenteric lymph node involvement

\footnotetext{
* Correspondence: paolo.sammartino@uniroma1.it

'Department of Surgery 'Pietro Valdoni', Sapienza University of Rome

Azienda Policlinico Umberto I, viale del Policlinico, 155, Rome, 00161, Italy

Full list of author information is available at the end of the article
} 


\section{Background}

Epithelial ovarian cancer is the fifth most frequent cause of cancer death in women and remains the leading cause of gynecologic cancer-related deaths in the US and Europe [1,2]. Although aggressive surgical cytoreduction and platinum- plus taxane-based chemotherapy have in recent years improved median overall survival in advanced ovarian cancer [3,4], relapse rates reach $80 \%$ and long-term cure rates languish between 20 and 30\% [4-6]. After a meta-analysis demonstrated the prognostic value of maximal cytoreduction [7], the definition of desirable surgical outcome switched from so-called 'optimal debulking' with variable residual disease up to 1 to $2 \mathrm{~cm}$ [8], to microscopic residual disease alone [9-12], justifying more aggressive surgery. To improve the outcome in treating patients with primary advanced or recurrent ovarian cancer, given the known benefits of normothermic intraperitoneal chemotherapy [13], some have combined cytoreduction (peritonectomy procedures) with hyperthermic intraperitoneal chemotherapy (HIPEC) [14-16].

As Hoffman et al. report, in about $26 \%$ of these patients the various visceral resections needed to reach maximal cytoreduction include colorectal resections [17]. Besides wide consensus on the need for colorectal resections to reduce residual disease, many investigators also emphasize the acceptable complications rate and the fact that, in most cases, the colorectum can be resected, avoiding an intestinal stoma $[18,19]$. Some compared the long-term results in patients who needed a colorectal resection (for example a rectosigmoid resection) and those in whom it could be avoided simply by removing the peritoneum in the Douglas pouch. Hardly surprisingly, they found that the results in the two groups overlapped [20] because outcomes in patients with advanced ovarian cancer depend crucially on the completeness of cytoreduction achieved, regardless of the surgical procedures used. No studies have yet clearly identified prognostic factors linking colorectal resection required during cytoreduction in these patients with survival.

Seeking a better guide to surgical management, we designed this study to assess anatomopathological outcome variables correlated with large-bowel involvement in patients with primary advanced or recurrent ovarian cancer with diffuse peritoneal metastases. To do so, from a larger consecutive series of prospectively enrolled patients with advanced ovarian cancer treated in our center with peritonectomy procedures and HIPEC, we selected for study those patients in whom cytoreduction required colorectal resections. Univariate and multivariate regression analyses were used to determine the prognostic value of several outcome variables including completeness of cytoreduction, depth of bowel wall invasion and lymph node spread.

\section{Methods}

From a phase II trial including a cohort of 70 patients with primary advanced or recurrent ovarian cancer with diffuse peritoneal metastases treated with peritonectomy and HIPEC from November 2000 to April 2009, we selected for study the 52 consecutive patients who had ovarian implants invading at least a single colorectal segment confirmed by intraoperative assessment and requiring colorectal resection. Colorectal resection was required because macroscopic disease in the colorectal segment, pouch or mesentery or both made it impossible to clear in situ malignant implants or attempt serosal stripping of the visceral surface. The inclusion criteria for peritonectomy were age younger than 75 years; histologically or cytologically confirmed diagnosis; performance status 0 to 2 (WHO); adequate cardiac, renal, hepatic and bone marrow function; resectable disease; and informed written consent. The exclusion criteria were extra-abdominal metastases; other malignancies except breast cancer; unresectable disease; active infection or severe associated medical conditions. The extent of malignant peritoneal disease was assessed with the peritoneal cancer index (PCI) - a scoring system ranging from 0 to 39 according to the extent of metastasis into the peritoneal cavity [21]. The completeness of cytoreduction (CC) was scored as $\mathrm{CC} 0$ : no residual disease; CC1: residual nodules measuring less than $2.5 \mathrm{~mm}$; CC2: residual nodes measuring between $2.5 \mathrm{~mm}$ and $2.5 \mathrm{~cm}$; and CC3 residual nodules greater than $2.5 \mathrm{~cm}$ [22]. Aggressive surgical cytoreduction followed the standard accepted techniques for peritonectomy [23].

When the tumor mass involved the pelvis, cul-de-sac, uterus and adnexa and rectosigmoid colon, or recurrent bulky disease involved the pelvis, maximal cytoreductive surgery usually comprised an en bloc resection including the internal female genitalia or pelvic recurrence along with the rectum and sigmoid, according to the pelvic peritonectomy technique [23]. Our policy envisaged a low distal rectal section just above the pelvic diaphragm, comprising the mesorectum, leaving a rectal stump no longer than $5 \mathrm{~cm}$. The inferior mesenteric artery was tied at its origin from the aorta and the vein at the ligament of Treitz. Patients with peritoneal implants involving the cecum, appendix, terminal ileum or ascending colon underwent a standard right hemicolectomy. In patients with diffuse colonic involvement, every effort was made to preserve as much colon as possible by clearing malignant implants from the surface [24]. Patients with peritoneal spread involving the pelvis and all colonic segments, with nodules penetrating deeply into the colonic wall, underwent total colectomy and rectal resection.

When each surgical procedure ended, HIPEC was given under general anesthesia with the closed technique and during hemodynamic monitoring. Cisplatin at a dose of 
$75 \mathrm{mg} / \mathrm{m}^{2}$ at inflow temperatures ranging from 42 to $43^{\circ} \mathrm{C}$ was given for 60 minutes. The technique used for HIPEC has been detailed in our preceding work [14].

The patients were admitted to the intensive care unit (ICU) for at least the first 24 hours after operation. Cisplatin toxicity, surgical complications and adverse events were graded from 0 to $\mathrm{V}$ according to the National Cancer Institutes Common Toxicity Criteria $[25,26]$.

All patients were followed up by members of the surgical staff and referred to the medical oncologic staff to plan systemic chemotherapy. Outpatient clinic visits for follow-up assessment were scheduled according to the individual patient's conditions.

Anatomopathological features studied in detail for each patient included the depth of malignant bowel wall invasion (serosal, muscle and mucosal layers) and lymph node spread. Lymph nodes were identified, taking into account dual polarity (locoregional and mesenteric) lymph node spread, and classified by site, distinguishing between locoregional ovarian (pelvic, obturator and interaortocaval stations) and mesenteric (pericolic, and mesorectal) nodes.

A multiple regression analysis was used to test correlations between possible prognostic factors. Survival was expressed as median months, and as five-year overall and disease-free rates. The Kaplan-Meier method was used to construct survival curves and the log-rank test (univariate analysis) was used to assess the significance of differences between curves. The Cox multivariate regression model was used to determine the prognostic value of independent variables. $P$ values $<0.05$ were considered to indicate statistical significance. The NCSS package (NCSS, LLC, Kaysville, UT, USA) was used to analyze the database and conduct statistical tests.

All patients gave their informed consent to the study. The procedures were approved by the institutional review board at Policlinico Umberto I Rome and the research complied with the Helsinki Declaration.

\section{Results}

Patients' demographic and clinical characteristics are reported in Table 1.

In the 52 patients selected for study because malignant disease required colorectal resections, peritonectomy procedures during cytoreduction comprised a mean number of 7.5 resections per patient (Table 2). During primary cytoreductive surgery, ovarian locoregional lymph nodes were routinely dissected whereas during secondary cytoreductive surgery, they were dissected in only 10 of the 22 patients who underwent cytoreduction because the procedure had not been done at the first operation. All the 52 patients selected because they underwent colorectal resection had site-specific mesenteric lymphadenectomy (Table 2).
Table 1 Patients' demographic and clinical characteristics (52 patients)

\begin{tabular}{|c|c|}
\hline Characteristics & $\mathrm{N}(\%)$ \\
\hline Age (years) & mean 62 (range 32-76) \\
\hline Primary cytoreduction & $30(57.7 \%)$ \\
\hline Secondary cytoreduction & $22(42.3 \%)$ \\
\hline \multicolumn{2}{|l|}{ Previous chemotherapy } \\
\hline None & $22(42.3 \%)$ \\
\hline Adjuvant & $22(42.3 \%)$ \\
\hline Neoadjuvant & $8(15.4 \%)$ \\
\hline \multicolumn{2}{|l|}{ Performance status (WHO) } \\
\hline 0 & $18(34.6 \%)$ \\
\hline 1 & $17(32.7 \%)$ \\
\hline 2 & $17(32.7 \%)$ \\
\hline \multicolumn{2}{|l|}{ Intestinal obstruction } \\
\hline Absent & $35(67.3 \%)$ \\
\hline Present & $17(32.7 \%)$ \\
\hline \multicolumn{2}{|l|}{ Ascites } \\
\hline Absent & $19(36.5 \%)$ \\
\hline Present & $33(63.5 \%)$ \\
\hline \multicolumn{2}{|l|}{ Comorbidity } \\
\hline Absent & $38(73.1 \%)$ \\
\hline Present & $14(26.9 \%)$ \\
\hline Ca125 level & $\begin{array}{c}\text { mean } 579.25 \mathrm{U} / \mathrm{ml} \text { (range } 15 \\
\text { to } 6800 \mathrm{U} / \mathrm{ml} \text { ) }\end{array}$ \\
\hline Peritoneal cancer index (PCI) & mean 18.8 (range 6 to 28) \\
\hline
\end{tabular}

Complete cytoreduction (CC-0) was achieved in 28 (53.8\%) of the patients, CC-1 in 17 (32.7\%), CC-2 in 5 (9.6\%) and $\mathrm{CC}-3$ in 2 (3.8\%), yielding an $86.5 \%$ rate of optimal cytoreduction (CC-0 and CC-1).

Peritonectomy procedures lasted a mean 510 minutes (range 300 to 780 ) including 60 minutes HIPEC. All operations led to major blood loss (mean $1700 \mathrm{ml}$, range 500 to 4900 ) and required intraoperative blood (mean 4 , range 2 to 8 units) and plasma (mean 6, range 2 to 10 units) transfusions.

Most patients (52\%) had an uneventful postoperative course. The only HIPEC-related adverse events were renal cisplatin toxicity ( 2 cases, grade 1 in one and grade 2 in the other patient), and medical treatment reversed both drug-induced reactions.

Grade I/II complications developed in $23.1 \%$, grade III in $7.7 \%$ and grade IV in $13.4 \%$ of the patients. Of the seven patients with grade IV complications, six underwent a second operation, two for colonic fistulas both unrelated to colorectal anastomoses but caused by the surgical maneuvers needed to ablate colonic implants, two for postoperative bleeding, one patient for a small bowel fistula due to a perforation that developed during 


\begin{tabular}{lc} 
Table 2 Types of resection during peritonectomy \\
(52 patients) \\
\hline Type of colorectal resection & $\mathbf{N}(\%)$ \\
\hline Rectal resection + left hemicolectomy & $24(46.1 \%)$ \\
Rectal resection + total colectomy & $18(34.6 \%)$ \\
Rectal resection + right hemicolectomy and & $6(11.5 \%)$ \\
left hemicolectomy & \\
Right hemicolectomy & $4(7.7 \%)$ \\
Total & $52(100 \%)$ \\
Associated visceral resections & $\mathrm{N}(\%)$ \\
Hysterectomy \pm adnexectomy & $35(67.3 \%)$ \\
Pelvic mass resection & $6(11.5 \%)$ \\
Omental resection & $49(94.2 \%)$ \\
Liver resection & $2(3.8 \%)$ \\
Cholecystectomy & $14(26.9 \%)$ \\
Splenectomy & $28(53.8 \%)$ \\
Small bowel resection & $16(30.8 \%)$ \\
Appendectomy & $11(21.1 \%)$ \\
Total cystectomy & $1(1.9 \%)$ \\
Bladder resection & $3(5.8 \%)$ \\
Total peritonectomy & $10(19.3 \%)$ \\
Partial peritonectomy & $42(80.7 \%)$ \\
Redominal wall resection & $13(25 \%)$ \\
Total surgical procedures & $51(92.7 \%)$ \\
\hline & $40(76.9 \%)$ \\
Vaginal resection or reduction of cancer implants & $12(23.1 \%)$ \\
\hline
\end{tabular}

pancreatitis, and one for an abdominal eventration. One patient returned to the ICU on postoperative day 6 after a myocardial infarction. Two patients died of pulmonary embolism despite anticoagulant treatment (operative mortality $3.8 \%$ ). Mean postoperative stay was 21.6 days (range 8 to 90). After hospital discharge all but two patients were fit for postoperative systemic chemotherapy.

Histopathology typed most tumors (71.5\%) as serous carcinomas followed by mucinous carcinoma (17.3\%), and endometrioid cancer (11.5\%). In all 52 cases malignant implants infiltrated the colorectal wall: in $13(25 \%)$ the serosa; in 35 (67.3\%) the muscular; and in 4 (7.7\%) reaching the mucosal layer. Multiple regression analysis showed that the depth of bowel wall involvement significantly correlates with more extensive peritoneal spread $(\mathrm{PCI}>18)$ and with overall lymph node metastases (Table 3).

Seeking dual polarity nodal spread, in the 52 patients we examined a mean of 24.3 (range 7 to 49 ) locoregional ovarian lymph nodes and a mean of 27.3 (range 14 to 60) mesenteric and mesorectal nodes per patient. Lymph node metastases were detected in $50 \%$ of the patients and involved the mesenteric nodes more frequently than the ovarian locoregional nodes $(30.8 \%$ vs. $7.7 \%)$, and in $11.5 \%$ of the cases involved both stations (Table 3). Of the 48 patients who underwent a rectal resection, 20 (41.6\%) had mesorectal lymph node metastases. Of the prognostic variables assessed (depth of colorectal wall invasion, number of colorectal resections, presence of locoregional node metastases and extent of peritoneal involvement), the only predictive factor that correlated significantly with mesenteric node metastases was the number of colorectal resections $(P<0.01)$ (Table 3$)$.

At a mean follow-up of 73.5 months (range 36 to 118), the overall five-year Kaplan-Meier survival rate in the 52 patients was $49.9 \%$ and the disease-free survival rate was $36.7 \%$. The overall median survival was 28 months and the median disease-free survival was 20 months. For the patients optimally debulked (CC-0 and CC-1) survival reached a value of 35.5 months overall and 32.5 months disease-free.

Univariate analysis (log-rank test) identified as the prognostic factors significantly correlated with long-term (five-year) survival, the $\mathrm{CC}$ score $(P<0.002)$ and degree of colorectal-wall involvement $(P<0.037)$. Cox regression model verifying the relationship between survival and combined prognostic factors confirmed that the only independent variables significantly influencing patients' survival were $\mathrm{CC}$ score $(P<0.003)$ and depth of colorectal-wall involvement $(P<0.004)$ (Table 4$)$.

\section{Discussion}

For this study, from a larger series of patients who underwent cytoreductive surgery plus HIPEC for primary advanced or recurrent ovarian cancer with diffuse peritoneal metastases, we explicitly selected those in whom cytoreduction included colorectal resections. This selection criterion allowed us to confirm and extend current knowledge on anatomopathological factors correlated with large bowel involvement that could influence outcome and survival. In our series, surgical cytoreduction called frequently for colorectal resections (52 in the original series of 70 patients, $74.3 \%$ ) because, as a tertiary referral center for the integrated treatment of peritoneal carcinomatosis, the patients we treat typically have a high index of peritoneal spread (mean PCI 18.8 , range 6 to 28 ).

When we compared our results with those of others who analyzed the surgical specimens removed in detail [20,27-35] - investigating the depth of invasion into the large bowel wall, mesenteric lymph node spread, their relation to survival, and overall survival in patients who underwent optimal cytoreduction - several distinctive 
Table 3 Anatomopathological outcome variables (52 patients)

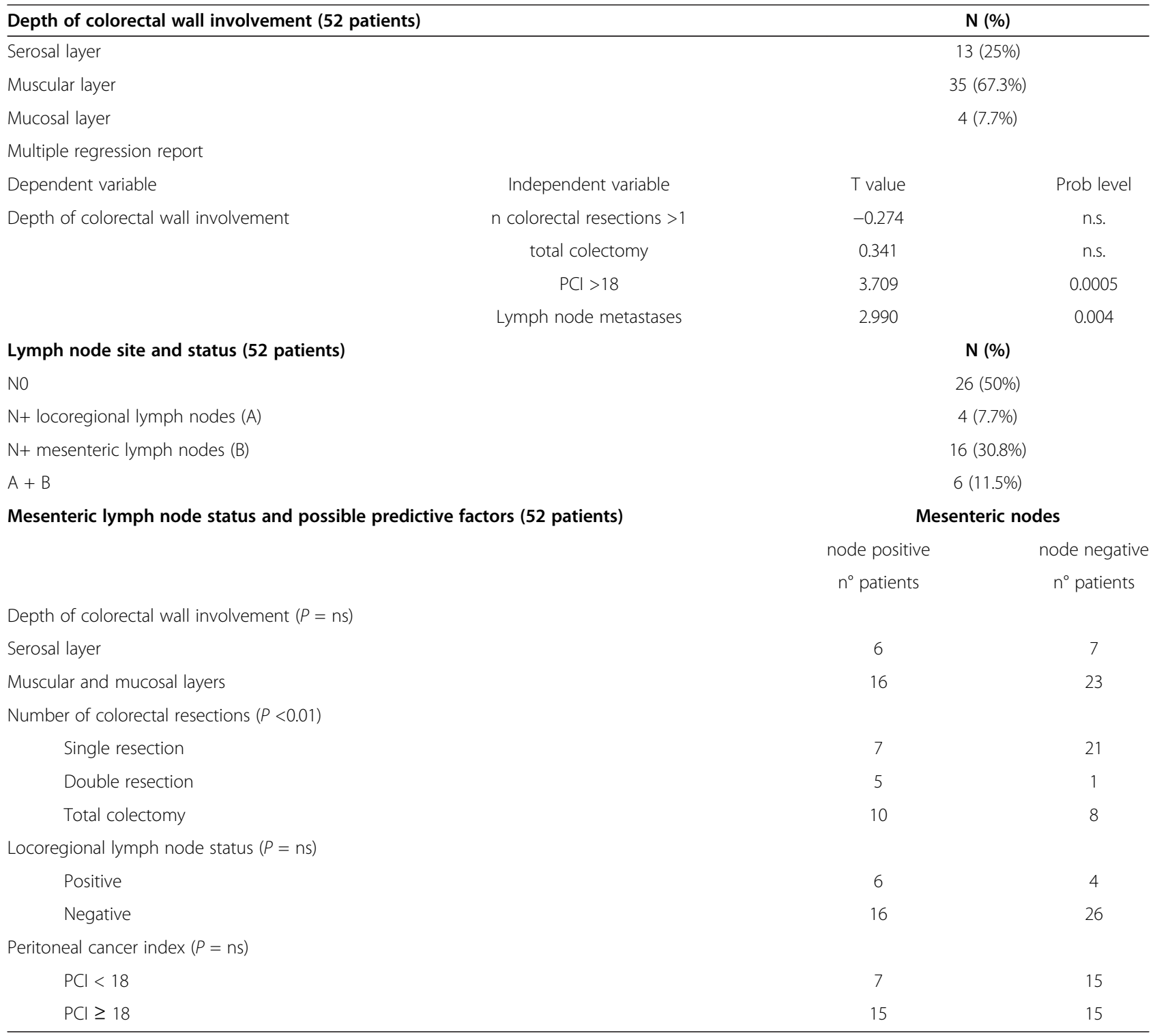

findings emerged (Table 5). The major observation was that the Cox regression analysis identified the depth of colorectal wall invasion as an independent prognostic factor statistically equal to the amount of residual disease (Table 4). None of the patients in whom large bowel wall invasion reached the mucosa survived more than three years. The considerable prognostic importance that the depth of invasion into the large bowel wall attained in our series partly agrees with the only two similar previous reports that underlined this finding $[29,31]$. In the series conducted by Scarabelli et al. the depth of large bowel wall invasion achieved prognostic value in the multivariate analysis only in patients with co-existing mesenteric lymph node metastases [29]. Conversely, in the patients studied by Park et al. this variable attained significant prognostic value in the log-rank test only for the disease-free interval whereas the significance disappeared when they analyzed overall survival [31]. We attribute the strong prognostic value for the depth of large bowel wall invasion to the lower percentage of patients with serosal invasion alone in our series than in others (serosal layers $25 \%$ vs. a mean of $44.5 \%$ ) and to the higher mean percentage of patients with malignant disease infiltrating deep into the large bowel wall (muscular and mucosal layers $75 \%$ vs. mean $55.4 \%)(P<0.01)$ (Table 5). The worse outcome in patients with deeper large bowel wall involvement can be explained by the multiple regression analysis showing that the depth of 
Table 4 Prognostic factors and five-year survival by univariate and multivariate analysis (52 patients)

\begin{tabular}{|c|c|c|c|c|}
\hline Prognostic factors & Variables & Five-year survival & $P^{*}$ (univariate analysis) & $P^{* *}$ (multivariate analysis) \\
\hline \multirow[t]{2}{*}{ Patients' age (years) } & $<62$ & $52.2 \%$ & 0.49 & 0.79 \\
\hline & $\geq 62$ & $41.2 \%$ & & \\
\hline \multirow[t]{2}{*}{ Ascites } & Absent & $39.2 \%$ & 0.97 & 0.08 \\
\hline & Present & $47.5 \%$ & & \\
\hline \multirow[t]{2}{*}{ Obstruction } & Absent & $56.7 \%$ & 0.64 & 0.59 \\
\hline & Present & $25.4 \%$ & & \\
\hline \multirow[t]{2}{*}{ Cytoreduction } & Primary & $47.2 \%$ & 0.98 & 0.73 \\
\hline & Secondary & $37.4 \%$ & & \\
\hline \multirow[t]{2}{*}{ Peritoneal cancer index } & $<18$ & $53.5 \%$ & 0.08 & 0.17 \\
\hline & $\geq 18$ & $33.6 \%$ & & \\
\hline \multirow[t]{2}{*}{ Completeness of cytoreduction score } & CC-0 & $55 \%$ & 0.002 & 0.003 \\
\hline & CC $1-3$ & $25.7 \%$ & & \\
\hline \multirow[t]{3}{*}{ Depth of colorectal wall involvement } & Serosal layer & $72.7 \%$ & 0.037 & 0.004 \\
\hline & Muscular layer & $33.1 \%$ & & \\
\hline & Mucosa layer & $0 \%$ & & \\
\hline \multirow[t]{4}{*}{ Lymph node status } & NO & $41.3 \%$ & 0.67 & 0.76 \\
\hline & $N+(A)$ & $75 \%$ & & \\
\hline & $\mathrm{N}+(\mathrm{B})$ & $42.5 \%$ & & \\
\hline & $\mathrm{N}+(\mathrm{A}+\mathrm{B})$ & $27.7 \%$ & & \\
\hline
\end{tabular}

$P^{*}$ by log-rank test; $P^{* *}$ by Cox regression model. $A$, locoregional lymph nodes; $B$, mesenteric lymph nodes.

bowel wall involvement correlates significantly with more extensive peritoneal spread $(\mathrm{PCI}>18)$ and with overall lymph-node metastases (Table 3).

The second finding in our series, in which cytoreductive surgery with colorectal resection invariably included mesenteric lymphadenectomy, was the $42.3 \%$ frequency of metastatic spread to the mesenteric lymph nodes. This frequency accords with the figure reported by Dvorethsky et al. reported in an autopsy study on 100 patients [36]. In the studies we analyzed (Table 5), the wide variability in metastatic mesenteric node spread - from 15.2\% reported by Park et al. [31] to 93.5\% reported by Salani et al. [33] - presumably depends on the lack of a systematic surgical protocol for mesenteric lymphadenectomy in these patients [33]. Some investigators underline that the frequency of mesenteric lymph node spread correlates significantly with certain pathologic variables [28,31,33]. For example, Park et al. related malignant mesenteric lymph node spread to the depth of colorectal wall invasion [31], Salani et al. to retroperitoneal lymph-node spread [33] and Lax et al. to the amount of colorectum resected [28]. In their later study Baiocchi et al. found a significant correlation between mesenteric lymph node spread and the depth of colorectal wall invasion and the presence of metastases at the retroperitoneal lymph node stations [34]. Our experience underlines that whenever metastatic peritoneal spread in advanced ovarian cancer invades the colorectal wall, one can reasonably expect mesenteric lymph node involvement equal to or even greater than that in the typical pelvic and interaortocaval locoregional lymph node stations (Table 3). The incidence of these metastases correlates significantly with number of colorectal segments involved and the extent of colorectal resections undertaken (Table 3), as Lax et al. have underlined [28]. When we analyzed the site of the involved mesenteric lymph node stations, in $41.6 \%$ of the patients in whom cytoreduction required a rectal resection we found evident metastatic spread to the mesorectal lymph nodes, alone or in association with other sites. Our finding and the $39.4 \%$ recently reported by Gouy et al. [35], fully justify our decision to base our surgical strategy on the general criteria for surgical oncology. In patients in whom malignant disease infiltrated deep into the peritoneal pouch and intraperitoneal rectum, we used an approach analogous to that generally used for rectal cancer, namely an almost total mesorectal excision. In our series, neither the univariate nor the multivariate analysis identified overall lymph node status as a significant prognostic indicator. Although concurrent locoregional ovarian and mesenteric lymph node involvement worsened patients' outcomes the difference failed to reach statistical significance. This finding agrees with O'Hanlan et al. and Lax et al. who reported that mesenteric lymph-node involvement worsened the outlook though not significantly $[27,28]$. Others more recently, Gallotta et al. [20], and Gouy et al. [35], reported similar survival in patients with 
Table $\mathbf{5}$ Colorectal involvement in advanced ovarian cancer: literature review

\begin{tabular}{|c|c|c|c|c|c|}
\hline Author/year & $\begin{array}{l}\text { Patients } \\
\text { (number) }\end{array}$ & $\begin{array}{l}\text { Depth of bowel wall } \\
\text { involvement (\%) }\end{array}$ & $\begin{array}{l}\text { Mesenteric nodal } \\
\text { involvement (\%) }\end{array}$ & $\begin{array}{l}\text { Prognostic significance of } \\
\text { pathological variables }\end{array}$ & $\begin{array}{l}\text { Survival of optimally } \\
\text { debulked patients }\end{array}$ \\
\hline \multirow{4}{*}{$\begin{array}{l}\text { O'Hanlan [27] } \\
\text { (1995) }\end{array}$} & \multirow[t]{4}{*}{66} & Serosa 41 & \multirow[t]{4}{*}{72.7} & \multirow{4}{*}{$\begin{array}{l}\text { Trend for patients with mesenteric } \\
\text { nodal involvement to fail sooner }\end{array}$} & \multirow[t]{4}{*}{26 months } \\
\hline & & Muscolaris 42 & & & \\
\hline & & Submucosa 14 & & & \\
\hline & & Mucosa 3 & & & \\
\hline \multirow{3}{*}{$\begin{array}{l}\operatorname{Lax}[28] \\
(1998)\end{array}$} & \multirow[t]{3}{*}{31} & Serosa 45 & \multirow[t]{3}{*}{64.5} & \multirow{3}{*}{$\begin{array}{l}\text { Trend for patients with mesenteric } \\
\text { nodal involvement to fail sooner }\end{array}$} & \multirow[t]{3}{*}{21 months } \\
\hline & & Muscolaris 36 & & & \\
\hline & & Mucosa 19 & & & \\
\hline \multirow{2}{*}{$\begin{array}{l}\text { Scarabelli [29] } \\
\text { (2000) }\end{array}$} & \multirow[t]{2}{*}{66} & \multirow[t]{2}{*}{ Muscolaris 100} & \multirow[t]{2}{*}{37.9} & \multirow{2}{*}{$\begin{array}{l}\text { Prognostic significance of depth of } \\
\text { bowel wall involvement at multivariate } \\
\text { analysis for patients with mesenteric } \\
\text { node metastases }\end{array}$} & 5 years \\
\hline & & & & & $42.2 \%$ \\
\hline \multirow{3}{*}{$\begin{array}{l}\text { Hertel [30] } \\
\text { (2001) }\end{array}$} & \multirow[t]{3}{*}{73} & Serosa 38.5 & \multirow[t]{3}{*}{ Not reported } & \multirow[t]{3}{*}{ Not reported } & \multirow[t]{3}{*}{ Not reported } \\
\hline & & Muscolaris 42.4 & & & \\
\hline & & Mucosa 19.1 & & & \\
\hline \multirow{2}{*}{$\begin{array}{l}\text { Park [31] } \\
\text { (2006) }\end{array}$} & \multirow[t]{2}{*}{46} & Serosa 71.7 & \multirow[t]{2}{*}{15.2} & \multirow{2}{*}{$\begin{array}{l}\text { Prognostic significance of depth of } \\
\text { bowel wall involvement only } \\
\text { for disease-free survival }\end{array}$} & \multirow[t]{2}{*}{32 months } \\
\hline & & $\begin{array}{l}\text { Muscolaris + mucosa } \\
28.3\end{array}$ & & & \\
\hline \multirow{4}{*}{$\begin{array}{l}\text { Tebes [32] } \\
(2006)\end{array}$} & \multirow[t]{4}{*}{99} & Serosa 33.3 & Not reported & Not reported & Not reported \\
\hline & & Muscolaris 39.4 & & & \\
\hline & & Submucosa 13.1 & & & \\
\hline & & Mucosa 14.2 & & & \\
\hline Salani [33] & 31 & Serosa 48 & 93.5 & Not reported & Not reported \\
\hline & & Muscolaris 29 & & & \\
\hline & & Submucosa 7 & & & \\
\hline & & Mucosa 16 & & & \\
\hline Gallota [20] & 71 & Serosa 45 & 51 & NO & 38 months overall \\
\hline & & Muscolaris 25.4 & & & \\
\hline & & Submucosa 12.7 & & & 30 months disease-free \\
\hline & & Mucosa 16.9 & & & \\
\hline Baiocchi [34] & 41 & Serosa 34.1 & 70.7 & Not reported & Not reported \\
\hline & & Muscolaris 31.7 & & & \\
\hline & & Submucosa 14.6 & & & \\
\hline & & Mucosa 19.5 & & & \\
\hline Gouy [35] & 47 & Serosa 61.7 & 40.4 & NO & 4 years $60 \%$ \\
\hline$(2012)$ & & Muscolaris 19.1 & & & \\
\hline & & Submucosa 6.3 & & & \\
\hline & & Mucosa 12.7 & & & \\
\hline Present series & 52 & Serosa 25 & 42.3 & Prognostic significance of depth & 35.5 months overall \\
\hline & & Muscolaris 67.3 & & $\begin{array}{c}\text { of bowel wall involvement at } \\
\text { multivariate analysis }\end{array}$ & \\
\hline & & Mucosa 7.7 & & & 32.5 months disease-free \\
\hline
\end{tabular}

and without spread to mesenteric lymph nodes. The observation that mesenteric lymph-node metastases especially if associated with locoregional lymph-node metastases worsen the prognosis, though not significantly, underlines the need for systematic lymphadenectomy, a procedure that is valuable for disease staging and is also therapeutically useful. If unrecognized lymph node disease were left in situ, patients with and without mesenteric lymph node spread would presumably no longer have a similar outcome. 
Finally, if we analyze overall and disease-free survival in our series of patients with diffuse peritoneal spread from ovarian cancer in whom cytoreductive surgery included colorectal resection, our data rank high among the literature, especially given emerging evidence showing that diffuse ovarian peritoneal spread worsens outcomes [37].

\section{Conclusions}

In patients with primary advanced or recurrent ovarian cancer with diffuse peritoneal metastases and colorectal involvement, the depth of colorectal wall invasion seems to be an independent prognostic factor equal to residual disease. Even though consensus now regards colorectal resections when needed as an accepted procedure during cytoreduction, the depth of colorectal wall invasion in these patients could be especially useful as a new criterion for stratifying patients into prognostic classes, a need that others have underlined [6]. When the diagnostic work-up discloses malignant disease invading the colorectal wall up to the mucosal layer, neoadjuvant chemotherapy could help to down-stage the disease.

A major concern that surgeons and pathologists should be aware of and deal with in patients with primary advanced or recurrent ovarian cancer involving the large bowel is dual locoregional and mesenteric lymphatic spread. Our experience corroborates previous evidence that the surgical technique for colorectal resection in these patients should strictly follow the criteria used for colorectal cancer $[27,29]$.

\section{Competing interests}

The authors declare they have no conflict of interest.

\section{Authors' contribution}

PS, MC, ADG participated in the conception and design of the study. SS, FA, DB, TC, AC, MLF analyzed and interpreted the data. PS, MC, ADG drafted and critically revised the manuscript. PS, MC, ADG, MLF gave final approval of the definitive version. All authors read and approved the final manuscript.

\section{Author details}

'Department of Surgery 'Pietro Valdoni', Sapienza University of Rome Azienda Policlinico Umberto I, viale del Policlinico, 155, Rome, 00161, Italy. ${ }^{2}$ Department of Experimental Medicine, Sapienza University of Rome Azienda Policlinico Umberto I, viale del Policlinico, 155, Rome 00161, Italy. ${ }^{3}$ Department of Obstetrics and Gynecology, Sapienza University of Rome Azienda Policlinico Umberto I, viale del Policlinico, 155, Rome 00161, Italy.

Received: 3 October 2012 Accepted: 16 February 2013

Published: 9 March 2013

\section{References}

1. Jemal A, Siegel R, Ward E, Murray T, Xu J, Smigal C, Thun MJ: Cancer statistics, 2006. CA Cancer J Clin 2006, 56:106-130.

2. Ferlay J, Autier P, Boniol M, Heanue M, Colombet M, Boyle P: Estimates of the cancer incidence and mortality in Europe in 2006. Ann Oncol 2007, 18:581-592.

3. Zivanovic O, Aldini A, Carlson JW, Chi DS: Advanced cytoreductive surgery: American perspective. Gynecol Oncol 2009, Suppl 2:S3-S9.

4. Armstrong DK, Bundy B, Wenzel L, Huang HQ, Baergen R, Lele S, Copeland L, Walker JL, Burger RA, Gynecologic Oncology Group: Intraperitoneal cisplatin and paclitaxel in ovarian cancer. N Engl J Med 2006, 354:34-43.
5. Ozols RF, Bundy BN, Greer BE, Fowler JM, Clarke-Pearson D, Burger RA, Mannel RS, DeGeest K, Hartenbach EM, Baergen R: Phase III trial of carboplatin and paclitaxel compared with cisplatin and paclitaxel in patients with optimally resected stage III ovarian cancer: a Gynecologic Oncology Group study. J Clin Oncol 2003, 21:3194-3200.

6. Winter WE 3rd, Maxwell GL, Tian C, Carlson JW, Ozols RF, Rose PG, Markman M, Armstrong DK, Muggia F, McGuire WP: Prognostic factors for stage III epithelial ovarian cancer: a Gynecologic Oncology Group Study. J Clin Oncol 2007, 25:3621-3627.

7. Bristow RE, Tomacruz RS, Armstrong DK, Trimble EL, Montz FJ: Survival effect of maximal cytoreductive surgery for advanced ovarian carcinoma during the platinum era: a meta-analysis. J Clin Oncol 2002, 20: 1248-1259.

8. Piver MS, Baker T: The potential for optimal (less than or equal to $2 \mathrm{~cm}$ ) cytoreductive surgery in advanced ovarian carcinoma at a tertiary medical center: a prospective study. Gynecol Oncol 1986, 24:1-8.

9. Eisenkop SM, Friedman RL, Wang HJ: Complete cytoreductive surgery is feasible and maximizes survival in patients with advanced epithelial ovarian cancer: a prospective study. Gynecol Oncol 1998, 69:103-108.

10. Aletti GD, Dowdy SC, Gostout BS, Jones MB, Stanhope CR, Wilson TO, Podratz KC, Cliby WA: Aggressive surgical effort and improved survival in advanced-stage ovarian cancer. Obstet Gynecol 2006, 107:77-85.

11. Eisenhauer EL, Abu-Rustum NR, Sonoda Y, Aghajanian C, Barakat RR, Chi DS: The effect of maximal surgical cytoreduction on sensitivity to platinumtaxane chemotherapy and subsequent survival in patients with advanced ovarian cancer. Gynecol Oncol 2008, 108:276-281.

12. du Bois A, Reuss A, Pujade-Lauraine E, Harter P, Ray-Coquard I, Pfisterer J: Role of surgical outcome as prognostic factor in advanced epithelial ovarian cancer: a combined exploratory analysis of 3 prospectively randomized phase 3 multicenter trials: by the Arbeitsgemeinschaft Gynaekologische Onkologie Studiengruppe Ovarialkarzinom (AGO-OVAR) and the Groupe d'Investigateurs Nationaux Pour les Etudes des Cancers de l'Ovaire (GINECO). Cancer 2009, 115:1234-1244.

13. Elit L, Oliver TK, Covens A, Kwon J, Fung MF, Hirte HW, Oza AM: Intraperitoneal chemotherapy in the first-line treatment of women with stage III epithelial ovarian cancer. Cancer 2007, 109:692-702.

14. Di Giorgio A, Naticchioni E, Biacchi D, Sibio S, Accarpio F, Rocco M, Tarquini S, Di Seri M, Ciardi A, Montruccoli D, Sammartino P: Cytoreductive surgery (peritonectomy procedures) combined with hyperthermic intraperitoneal chemotherapy (HIPEC) in the treatment of diffuse peritoneal carcinomatosis from ovarian cancer. Cancer 2008, 113:315-325.

15. Chua TC, Robertson G, Liauw W, Farrell R, Yan TD, Morris DL: Intraoperative hyperthermic intraperitoneal chemotherapy after cytoreductive surgery in ovarian cancer peritoneal carcinomatosis: systematic review of current results. J Cancer Res Clin Oncol 2009, 135:1637-1645.

16. Helm CW, Richard SD, Pan J, Bartlett D, Goodman MD, Hoefer R, Lentz SS, Levine EA, Loggie BW, Metzinger DS, Miller B, Parker L, Spellman JE, Sugarbaker PH, Edwards RP, Rai SN: Hyperthermic intraperitoneal chemotherapy in ovarian cancer: first report of the HYPER-O registry. Int J Gynecol Cancer 2010, 20:61-69.

17. Hoffman MS, Zervose E: Colon resection for ovarian cancer: intraoperative decisions. Gynecol Oncol 2008, Suppl 2:S56-S65.

18. Mourton SM, Temple LK, Abu-Rustum NR, Gemignani ML, Sonoda Y, Bochner BH, Barakat RR, Chi DS: Morbidity of rectosigmoid resection and primary anastomosis in patients undergoing primary cytoreductive surgery for advanced epithelial ovarian cancer. Gynecol Oncol 2005, 99:608-614.

19. Juretzka MM, Barakat RR: Pelvic cytoreduction with rectosigmoid resection. Gynecol Oncol 2007, Suppl 1:40-44.

20. Gallotta V, Fanfani F, Vizzielli G, Panico G, Rossitto C, Gagliardi ML, Margariti PA, Salerno MG, Zannoni GF, Pacelli F, Scambia G, Fagotti A: Douglas peritonectomy compared to recto-sigmoid resection in optimally cytoreduced advanced ovarian cancer patients: analysis of morbidity and oncological outcome. Eur J Surg Oncol 2011, 37:1085-1092.

21. Jacquet $P$, Sugarbaker $P H:$ Clinical research methodologies in diagnosis and staging of patients with peritoneal carcinomatosis. In Peritoneal carcinomatosis: principle of management. Edited by Sugarbaker PH. Boston: Kluwer Academic, Volume 82; 1996:359-374.

22. Sugarbaker PH (Ed): Peritoneal carcinomatosis: principle of management. Boston: Kluwer Academic; 1996:155-161.

23. Sugarbaker PH: Peritonectomy procedures. Ann Surg 1995, 221:29-42. 
24. Bijelic L, Sugarbaker PH: Cytoreduction of the small bowel surfaces. I Surg Oncol 2008, 97:176-179.

25. National Cancer Institute: Common Terminology Criteria for Adverse Events (CTCAE) version 4.0; 2009. US National Institutes of Health. https:// webapps. ctep. nci. nih. gov / webobjs / ctc / webhelp / welcome_to_ctcae.htm.

26. Saxena A, Yan TD, Morris DL: A critical evaluation of risk factors for complications after cytoreductive surgery and perioperative intraperitoneal chemotherapy for colorectal peritoneal carcinomatosis. World I Surg 2010, 34:70-78.

27. O'Hanlan KA, Kargas S, Schreiber M, Burrs D, Mallipeddi P, Longacre T, Hendrickson M: Ovarian carcinoma metastases to gastrointestinal tract appear to spread like colon carcinoma: implications for surgical resection. Gynecol Oncol 1995, 59:200-206.

28. Lax SF, Petru E, Holzer E, Pertl AM, Ralph G, Greenspan DL, Berger A, Jatzko $\mathrm{G}$ : Mesenteric and mesocolic lymph node metastases from ovarian carcinoma: a clinicopathological analysis. Int J Gynecol Cancer 1998, 8:119-123.

29. Scarabelli C, Gallo A, Franceschi S, Campagnutta E, De G, Giorda G, Visentin MC, Carbone A: Primary cytoreductive surgery with rectosigmoid colon resection for patients with advanced epithelial ovarian carcinoma. Cancer 2000, 88:389-397.

30. Hertel H, Diebolder H, Herrmann J, Köhler C, Kühne-Heid R, Possover M, Schneider A: Is the decision for colorectal resection justified by histopathologic findings: a prospective study of 100 patients with advanced ovarian cancer. Gynecol Oncol 2001, 83:481-484.

31. Park JY, Seo SS, Kang S, Lee KB, Lim SY, Choi HS, Park SY: The benefits of low anterior en bloc resection as part of cytoreductive surgery for advanced primary and recurrent epithelial ovarian cancer patients outweigh morbidity concerns. Gynecol Oncol 2006, 103:977-984.

32. Tebes SJ, Cardosi R, Hoffman MS: Colorectal resection in patients with ovarian and primary peritoneal carcinoma. Am J Obst Gynecol. 2006, 195:585-589.

33. Salani R, Diaz-Montes T, Giuntoli RL, Bristow RE: Surgical management of mesenteric lymph node metastasis in patients undergoing rectosigmoid colectomy for locally advanced ovarian carcinoma. Ann Surg Oncol 2007, 14:3552-3557.

34. Baiocchi G, Cestari LA, Macedo MP, Oliveira RA, Fukazawa EM, Faloppa CC, Kumagai LY, Badiglian-Filho L, Menezes AN, Cunha IW, Soares FA: Surgical implications of mesenteric lymph node metastasis from advanced ovarian cancer after bowel resection. J Surg Oncol 2011, 104:250-254.

35. Gouy S, Goetgheluck J, Uzan C, Duclos J, Duvillard P, Morice P: Prognostic factors for and prognostic value of mesenteric lymph node involvement in advanced-stage ovarian cancer. Eur J Surg Oncol 2012, 38:170-175.

36. Dvoretsky PM, Richards KA, Angel C, Rabinowitz L, Stoler MH, Beecham JB, Bonfiglio TA: Distribution of disease at autopsy in 100 women with ovarian cancer. Hum Pathol 1988, 19:57-63.

37. Pereira A, Magrina JF, Magtibay PM, Pérez-Medina T, Fernández A, Peregrin I: The impact of peritoneal metastases in epithelial ovarian cancer with positive nodes. Int J Gynecol Cancer 2011, 21:1375-1379.

doi:10.1186/1477-7819-11-64

Cite this article as: Di Giorgio et al.: Depth of colorectal-wall invasion and lymph-node involvement as major outcome factors influencing surgical strategy in patients with advanced and recurrent ovarian cancer with diffuse peritoneal metastases. World Journal of Surgical Oncology 2013 11:64

\section{Submit your next manuscript to BioMed Central and take full advantage of:}

- Convenient online submission

- Thorough peer review

- No space constraints or color figure charges

- Immediate publication on acceptance

- Inclusion in PubMed, CAS, Scopus and Google Scholar

- Research which is freely available for redistribution 